\title{
Numerical modelling of anomalous microseismicity influenced by lithological heterogeneity in longwall top coal caving mining
}

\author{
Wenzhuo Cao ${ }^{a}$, Ji-Quan Shi ${ }^{a}$, Sevket Durucan ${ }^{a}$, Anna Korre ${ }^{a}$, Sergej Jamnikar ${ }^{b}$ \\ ${ }^{a}$ Department of Earth Science and Engineering, Royal School of Mines, Imperial College London, \\ London, SW7 2AZ, United Kingdom \\ ${ }^{\mathrm{b} C o a l}$ Mine Velenje, Partizanska 78, Velenje, Slovenia
}

Corresponding author: Wenzhuo Cao, w.cao15@imperial.ac.uk

\begin{abstract}
Mining-induced microseismicity has been extensively used to evaluate the potential for rock bursts and coal and gas outbursts in underground coal mines. In a research project completed a few years ago, it was observed that characteristics of microseismicity around a working longwall panel were fairly consistent over the monitoring period until a lithological heterogeneity zone with a relatively high coal strength was reached. The current research presented in this paper aims at achieving a better understanding of the effect of lithological heterogeneity on microseismic activity in longwall coal mining. The heterogeneous zone inferred from the tomography measurements was first digitalised and implemented into a 3D geomechanical model. A microseismicity modelling approach which combines deterministic stress and failure analysis together with a stochastic fracture slip evaluation was used to simulate the evolution of microseismicity induced by the progressive face advance passing through the heterogeneous zone. The heterogeneity was taken into account by varying the material strength and the fracture attributes of the elements within the high strength zone. Results have shown that both the high rock strength of coal lithotype and low power law scaling exponent of fractures within this zone contribute to the reduction in fitted $b$ values from frequency-magnitude distribution of microseismicity and the increase in fitted Gaussian distribution parameters to the logarithmic event energy. These deviations are believed to result from the combined effects of increased stress drops and slipped fracture sizes when the heterogeneous zone is approached.
\end{abstract}

Keywords: microseismicity; discrete fracture network (DFN); heterogeneity; longwall coal mining; seismic modelling

\section{Highlights:}

- Mining-induced microseismicity influenced by lithological heterogeneity was modelled.

- Heterogeneities in both material strength and fracture attributes were considered.

- Both high coal strength and low fracture scaling exponent lead to elevated seismic energy level.

- The recorded seismic anomaly results from increased stress drops and slipped fracture sizes. 


\section{Introduction}

Underground mining activities are usually accompanied by microseismic events. Extraction of large volumes of rocks at depth brings about changes in stress conditions around mine openings and beyond. It has been widely accepted that microseismicity is predominantly caused by slip of pre-existing planes of weakness (e.g. fractures) and geological discontinuities (e.g. faults) (Stiller et al., 1983; Spottiswoode, 1984).

Seismic events are typically characterised by the magnitude of released energy, event counts, and the scaling of microseismic event magnitude. Energy released from a microseismic event is predominantly dependent on fracture size, stress drop along the fracture surface, and rock properties (Salamon, 1993). The stress drop is in turn affected by the prevailing stress conditions and rock properties.

Occurrences of microseismic anomaly have been reported to be associated with geometric and structural complexities, such as bedding shear zones in coal seams and stiff structures in hard rock mines. The presence of these geological structures influences the rock mass response to loading conditions, and thus microseismic characteristics. For example, Sato and Fujii (1988) reported that the seismic energy release rate was significantly suppressed before passing through a fault in the hanging wall. It has been observed that the largest seismic events tended to fall into the largest vein in an American deep hard rock mine (Swanson, 1992). It was also reported that two stiff reef structures led to decreases in both seismic event rate and seismogenic movement rate in an Australian gold mine (Abolfazlzadeh and Hudyma, 2016).

The impact of local heterogeneity in rock properties such as permeability and strength on the response of rock masses to excavation has been studied numerically. For example, An and Cheng (2013) adopted a one-dimensional flow model with a low-permeability zone to study the gas distribution patterns, and showed that both the magnitude of permeability and the extent of the low-permeability zone affect the abundance of gas in the coal seam.

The impact of material heterogeneity arisen from geological structures such as faults or shear zones has been investigated by a number of researchers. Lei et al. (2004) conducted triaxial loading experiments on rock samples containing pre-existing joints with various strength and asperities, and found that while the failure of homogeneous faults gives no clear early warning signals and is unpredictable, heterogeneous faults fracture after a crack nucleation phase with distinct statistical variation of $\mathrm{AE}$ activity parameters. Sainoki and Mitri (2014) used a transversely isotropic, linear elastic model to verify the increase in fault-slip potential as a result of heterogeneity of shear stiffness in the weak zone. Zhao et al. (2014) modelled the response of the rock mass containing a brittle fault zone in TBM excavations, in which the Mohr-Coulomb yield criterion was adopted to evaluate the failure of the fault zone, and interface elements were used to represent the interaction between the fault and the rock mass. Xu et al. (2015) used an equivalent continuum approach to model a cavern excavation near an interlayer shear weakness zone, where the thickness, strength and orientation of the zone were characterised.

In a research project completed a few years ago, continuous microseismic monitoring was performed around a working longwall top coal caving (LTCC) panel at Coal Mine Velenje in Slovenia. During a monitoring period of twelve weeks in 2011, a seismic anomaly characterised by a decrease in event counts and an increase in the average seismic energy released was observed from the eighth week onwards. Also confirmed through time-lapse active seismic tomography in the same longwall panel, this anomaly has been attributed to a xylite-rich heterogenous zone with relatively high strength in an area dominated by detritic coal (Si et al., 2015a).

In a more recent research by the authors (Cao et al., 2018), a numerical modelling approach which includes sequential stress analysis and fracture slip evaluation was developed to model the microseismicity generation in longwall coal mining. The modelling approach was then applied to 
simulate microseismic occurrence and associated energy release prior to the same seismic anomaly at Coal Mine Velenje. The modelled microseismic characteristics were consistent over the coal production period, and matched well with field observations, validating the numerical model developed (Cao et al., 2018).

In order to investigate the effect of lithological heterogeneity on microseismic activity in longwall coal mining, the current research presented in this paper applies the same numerical modelling approach to model seismic characteristics during longwall coal extraction towards the heterogeneous zone inferred from the time-lapse seismic tomography. The rock strength of the elements and fracture attributes within the zone are varied, respectively. The induced microseismicity is investigated in terms of frequency-magnitude distribution and logarithmic energy of microseismic events. This model provides a tool to obtain a better understanding of factors influencing mining-induced microseismicity, and lays a foundation for the forecasting of rock bursts or coal and gas outbursts using recorded microseismic data.

\section{Longwall coal mining-induced microseismicity and modelling methodology}

Figure 1 presents a schematic diagram illustrating multi-level LTCC mining and the background for induced microseismicity as a result of fracture slippage in a thick coal seam. Pre-existing natural fractures within the seam as potential sources of microseismicity are projected to the cross section as $2 \mathrm{D}$ fracture traces. The distribution of fracture sizes can be characterised by the power law (Bonnet $e t$ al., 2001):

$$
n(l)=\alpha \cdot l^{-a}
$$

where $n(l)$ is the number of fractures with size in the range $[l, l+\mathrm{d} l]$ per unit volume, $\alpha$ is the fracture density term, and $a(>1)$ is the size scaling exponent which determines the relative number of fractures with different sizes within the population.

As depicted in Figure 1, a near face fracturing zone is formed in response to coal extraction, and the peak abutment zone resulting from overburden loads extends from the fractured zone into the far field. Progressive longwall coal mining constantly shifts the stress concentration ahead as the longwall face advances, increasing the slippage potential of underlying fractures at critical stress states. Fracture slippage is deemed to take place in the form of microseismicity when the prevailing stress states satisfy the Mohr-Coulomb slip criterion, i.e., the prevailing shear stress along the fracture plane exceeds the shear strength:

$$
\tau_{\mathrm{sf}}=\mu_{\mathrm{sf}} \sigma+c_{\mathrm{f}}
$$

where $\tau_{\mathrm{sf}}$ is the resistance to slip, $\sigma$ is the normal stress on the fracture surface, and $\mu_{\mathrm{sf}}$ and $c_{\mathrm{f}}$ are the static friction coefficient and the cohesion along the fracture, respectively.

The stress drop $\Delta \tau$ along the fracture plane can be considered as the difference between the resistance to shear slip $\tau_{\mathrm{sf}}$ and the dynamic shear strength $\tau_{\mathrm{df}}$ of the fracture surface:

$$
\Delta \tau=\tau_{\mathrm{sf}}-\tau_{\mathrm{df}}
$$

The released seismic energy from the stress drop can be calculated by:

$$
E_{\mathrm{k}}=\frac{4(1-v) \Delta \tau^{2} R^{3}}{3 G(1-v / 2)}
$$


where $v$ and $G$ are the Poisson's ratio and the shear modulus of the host rock respectively, $\Delta \tau$ is the stress drop magnitude and $R$ is the fracture size.

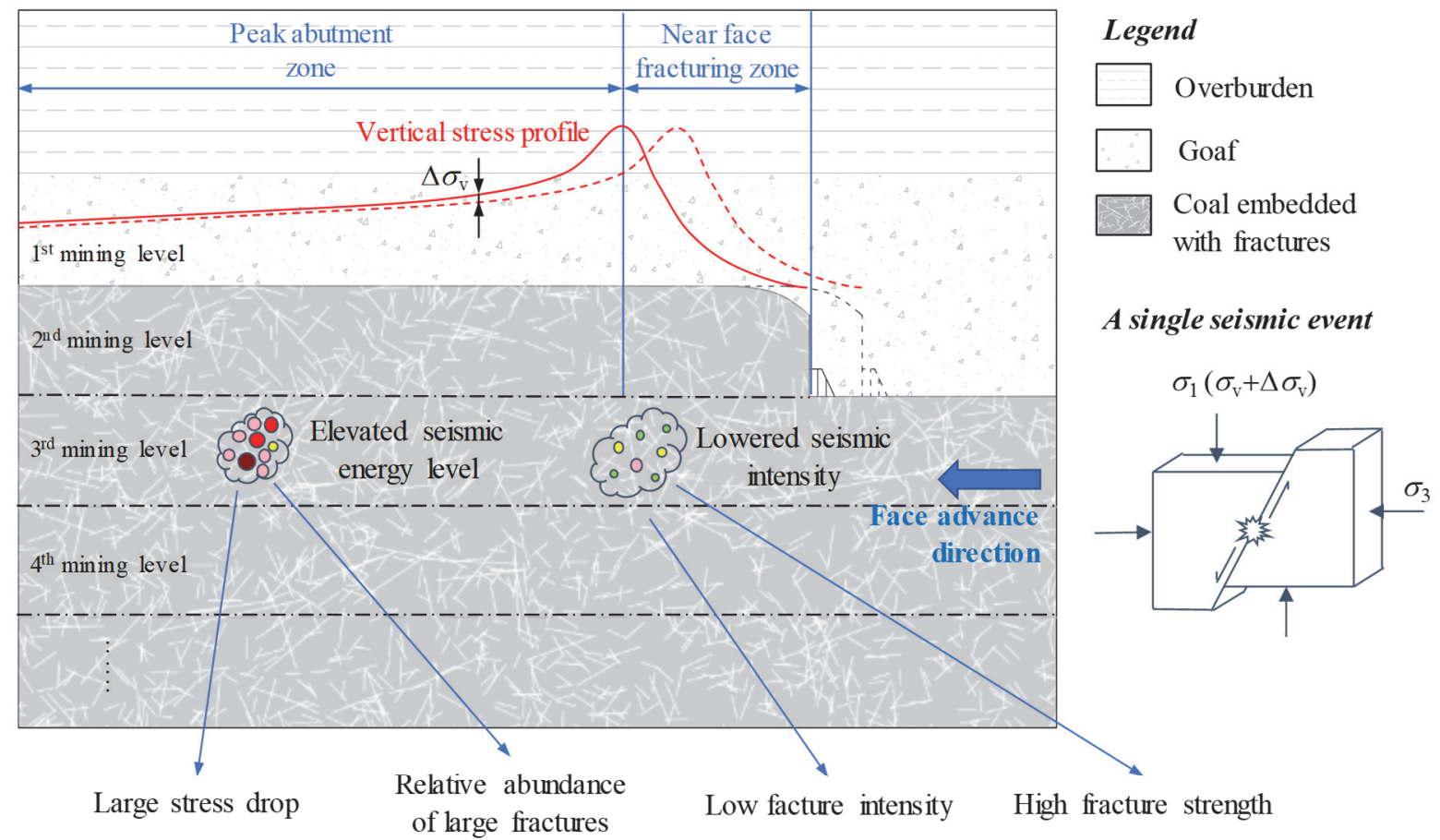

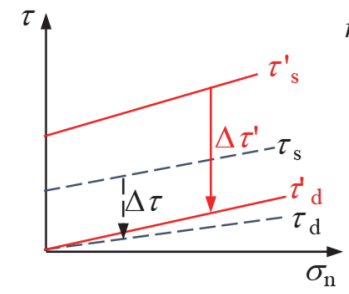

$\Delta \tau=\tau_{\mathrm{s}}-\tau_{\mathrm{d}}$

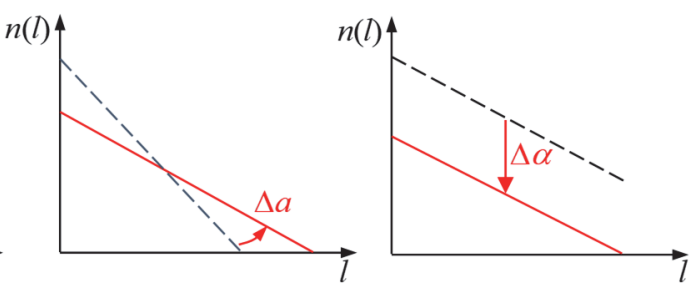

$n(l)=\alpha l^{-a}$

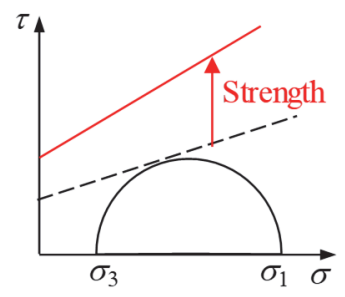

$\tau_{\mathrm{sf}}=\mu_{\mathrm{sf}} \sigma+c_{\mathrm{f}}$

Figure 1. Schematic illustration of the background for multi-level LTCC mining-induced microseismicity as a result of fracture slippage and possible mechanisms of microseismic anomaly.

Microseismic energy and intensity, therefore, are governed by both coal strength and fracture attributes. Given the same stress conditions, the heightened seismic energy level results from strength heterogeneity (large stress drop associated with coal strength), or fracture scaling heterogeneity (relative abundance of large fractures) (Figure 1). The reduced seismic intensity can be attributed to high fracture strength (which elevates the Mohr-Coulomb failure envelope) or low intensity of underlying natural fractures (which reduces the number of potential sources). The modelling methodology used to simulate anomalous microseismicity in this work is able to represent the effects of both strength properties of coal and attributes of underlying natural fractures.

In this study, a numerical approach which considers fracture slippage based on the stress and failure state of the model is applied to generate microseismicity in longwall coal mining. Salamon (1993) and Board (1994) were the first to implement fractures along which slip can take place to form a microseismic event in elastic models. The modelling is carried out by referring to the following procedure: 
(1) Model construction and fracture implementation: A model is first established in FLAC $^{3 \mathrm{D}}$ to represent the longwall panel layout and surrounding strata. Mechanical and strength properties are assigned to elements representing different geological structures, and an elasto-plastic constitutive model is applied to represent the rock mass failure behaviour in response to coal extraction. The initial and boundary conditions are then set up to simulate the in situ stress field in the coal mine.

The pre-existing fractures are implemented as potential microseismic hypocentres in the model domain. This is realised by the built-in discrete fracture network (DFN) logic in FLAC ${ }^{3 \mathrm{D}}$. The embedded fractures are planar and disk-shaped. The fracture attributes consist of fracture intensity, orientation, size range and size distribution. Considering shear slip as a predominant microseismicity mechanism, the fracture intensity can be estimated by event counts of recorded microseismicity. The fracture orientation can be specified according to field scanline surveys, or randomly sampled from a Gaussian distribution. The fracture size range and frequency-magnitude distribution can be estimated by the range and distribution of the recorded microseismic events.

(2) Stress and failure analysis: Progressive longwall mining is simulated by sequential excavation steps. At one excavation step, the elements representing both the coal to be extracted by the shearer and the caved top coal are "removed" from the model domain. The stress calculation and failure analysis are then performed alternately throughout the modelling process to update the stress state and determine if plastic failure occurs in response to coal production. In this way, the influence of post-failure behaviour of the rock mass on stress redistribution around excavations is taken into account. The modelling of each excavation step stops when no failure zones are formed and new stress equilibrium is reached. At the next excavation step, the removed elements are "reinstated" by assigning mechanical and strength properties of caved goaf materials to them.

(3) Microseismicity generation and calculation of released energy: After the stress equilibrium is reached in the model, all the fractures located in the elastic zone are traversed to check if fracture slippage takes place to generate a microseismic event. In view that fracture sizes may exceed those of zone elements, nine stress calculation points on each fracture surface, including eight uniformly located on the fracture circumference and one at the centroid of the fracture, are used. The stresses applied for evaluation are extracted from those for zone elements closest to these stress calculation points. Once the Mohr-Coulomb slip criterion at any stress calculation point is met, the fracture is considered to have slipped over the whole fracture surface and a microseismic event is thus formed. Fractures that have slipped once are marked and not allowed to slip in the following modelling steps.

\section{Recorded microseismic events and analysis at Coal Mine Velenje}

Coal Mine Velenje produces 3.4 million tonnes of lignite per annum from the largest coal deposit in Slovenia. The multi-level longwall top coal mining method, referred to as the Velenje Mining Method (Jeromel et al., 2010), is used at Coal Mine Velenje to mine a coal seam which is up to 160 metres thick in the centre of the coalfield.

As described in detail by Si et al. (2015a), time-lapse seismic tomography was performed over a $100 \mathrm{~m}$ $\times 141 \mathrm{~m}$ area ahead of the approaching longwall panel K.-50/C at $350 \mathrm{~m}$ depth below the ground level during May-June 2011 (Figure 2). Figure 3 presents the P-wave velocity tomograms of the 1st and 2nd campaigns for the $\mathrm{X}$ component when the longwall face was $95 \mathrm{~m}$ and $47 \mathrm{~m}$ away from the tomography area respectively. During the first time-lapse seismic tomography campaign, a relatively high velocity zone was detected diagonally across the centre of the tomography zone. This heterogeneous zone was considered to be xylite-rich coal with a relatively high strength, as compared to less strong detritic coal that dominates the coal deposit. The unconfined compressive strength of xylite in the deposit is known to be around twice of that for detrite. The second tomogram, taken when the LTCC face advanced 
further closer to the tomography zone, indicates even higher velocities over the heterogeneous zone, and much lower seismic velocities over the weaker coal, which is now closer to the advancing face, indicating intensified but preferential fracturing of the weaker coal due to abutment stresses.

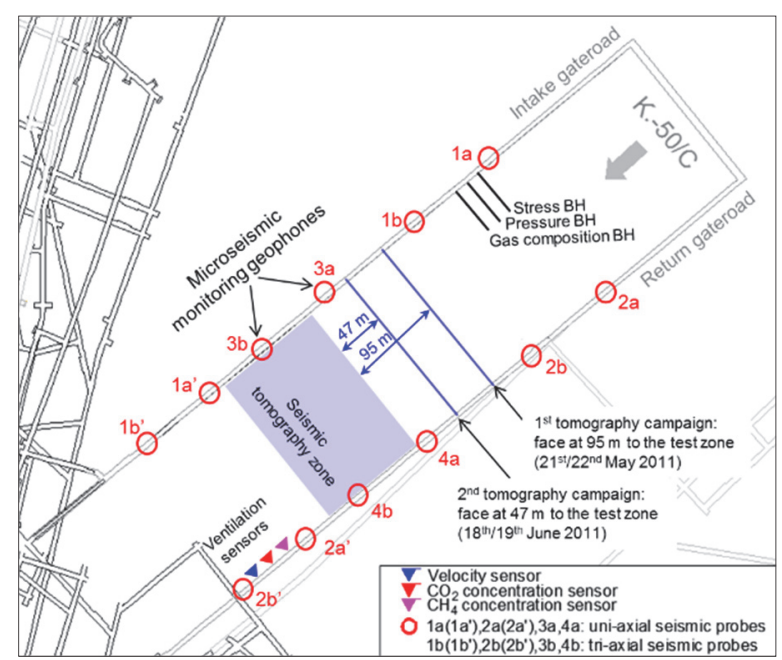

Figure 2. The time-lapse seismic tomography zone and the configuration of sensors used for microseismic monitoring and ventilation environment measurements at LTCC panel K.-50/C.

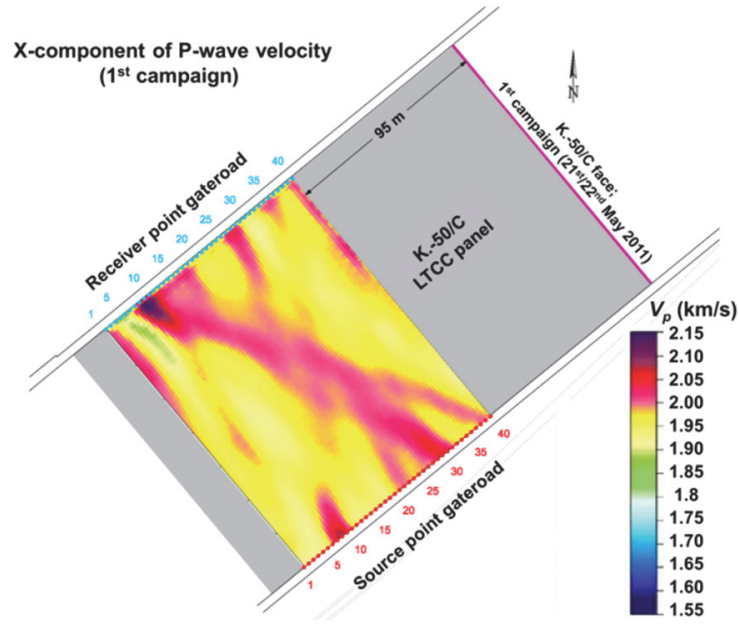

(a)

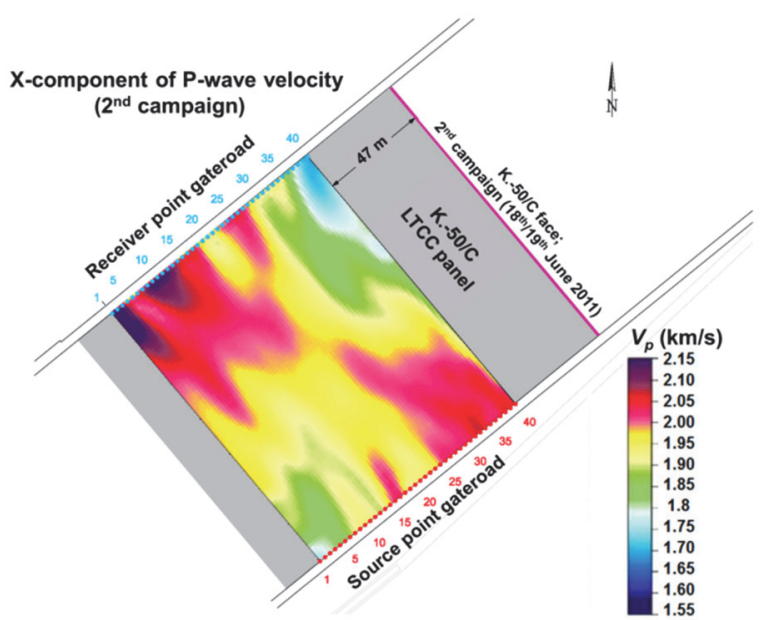

(b)

Figure 3. LTCC face K. -50/C P-wave velocity tomograms in X-component for the (a) $1^{\text {st }}$ and (b) $2^{\text {nd }}$ tomography campaigns (after Si et al., 2015a).

In order to assess the dynamic behaviour of the coal seam in response to longwall mining, continuous microseismic monitoring measurements were also carried out at the same panel during a twelve-week period from 23 May to 28 August 2011 ( $\mathrm{Si}$ et al., 2015a). This period included a two-week summer holiday from 18 to 31 July when there was no coal production and a very few microseismic events were recorded. When the longwall face reached the xylite-rich zone, a decrease in microseismic event counts accompanied by an increase in the average released seismic energy was observed (Figure 4a). 


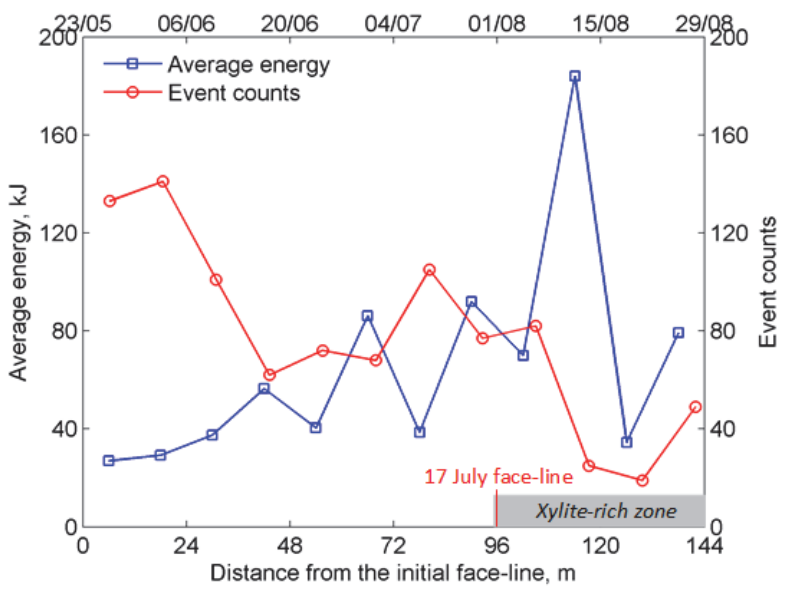

(a)

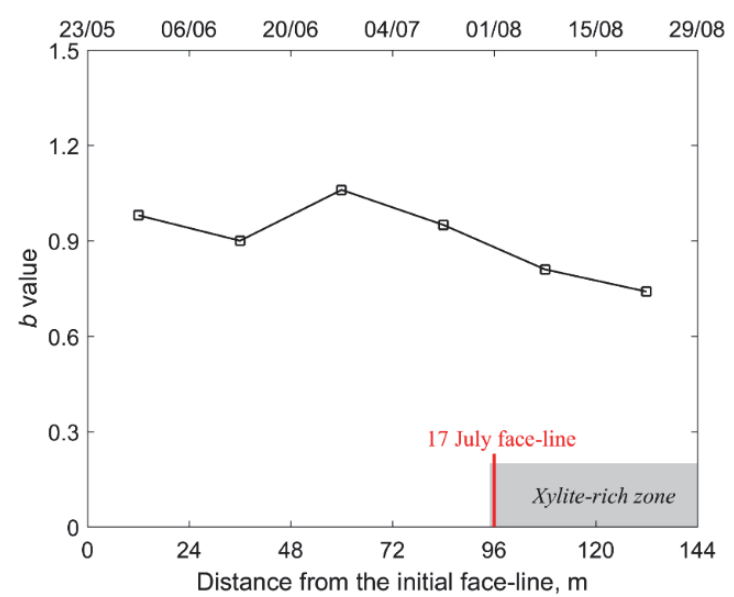

(b)

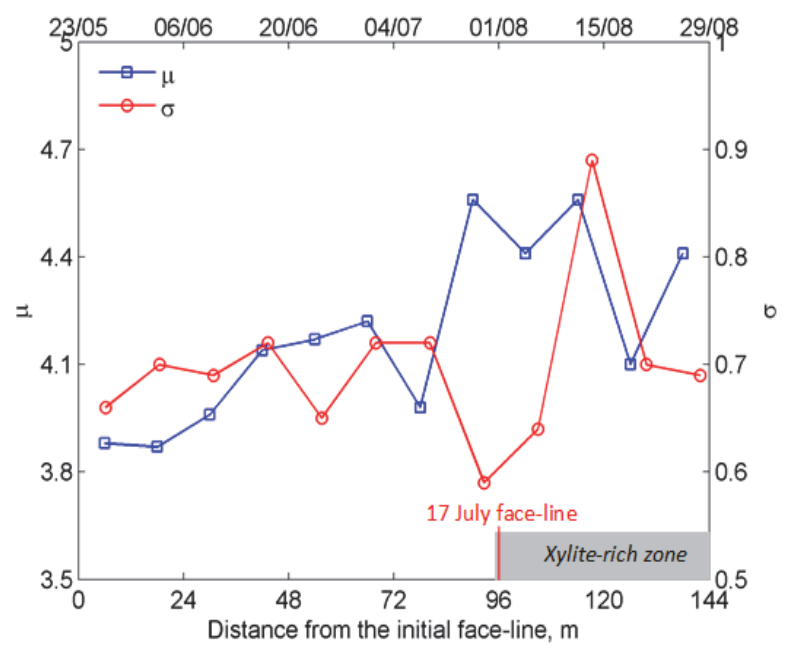

(c)

Figure 4. Characteristics of microseismicity monitored over a twelve-week period when the longwall face advanced towards the xylite-rich zone: (a) recorded weekly average released energy from microseismic events and event counts against face advance, (b) calculated $b$ values for frequency-magnitude distribution of microseismic events recorded during two consecutive production weeks, and (c) fitted Gaussian distribution parameters to the logarithmic event energy during each production week.

The analysis of the microseismic data has shown that the bi-weekly frequency-magnitude distribution of recorded microseismic events follows the Gutenberg-Richter relationship, with the $b$ value reflecting the scaling of microseismic event magnitude (Figure $4 \mathrm{~b}$ ). In addition, the weekly histogram of the released seismic energy follows a Gaussian distribution, which is characterised by the mean of the distribution $\mu$, and the standard deviation $\sigma$. It was observed that these features of microseismic events were quite steady in the first eight weeks, and deviated after reaching the xylite-rich zone (Figure 4c).

Considering that microseismic events primarily arise from fracture slippage, the $b$ value for the Gutenberg-Richter relationship is related to the scaling of fracture sizes in the coal seam. Similarly, the fitted mean value $\mu$ and standard deviation $\sigma$ of the Gaussian distribution are associated with the fracture sizes and size distribution, respectively. In view of the consistency in the $b$ values and fitted Gaussian distribution parameters ( $\mu$ and $\sigma$ ) during the first eight weeks, it was assumed that the fracture sizes and size distribution within the coal panel were consistent over this period. The deviations in the $b, \mu$ and $\sigma$ values, event counts and average energy release when approaching the xylite-rich zone suggest that, 
except for rock strength, the fractures within the xylite-rich zone also differ from those in the detritedominated coal seam.

Using a coupled DEM-DFN model, Harthong et al. (2012) have demonstrated that fractured rock mass embedded with DFNs following a power law size distribution has higher rock strength and elastic modulus for samples with lower fracture intensity, and tend to have greater rock strength for samples with lower fracture size distribution exponent $a$. In this respect, it is deduced that fractures within the xylite-rich zone have lower intensity and power law exponent $a$ related to their size distribution.

\section{Numerical simulation of anomalous microseismicity}

\subsection{Numerical model setup}

As reported in a previous publication by the authors (Cao et al., 2018), a DFN-based numerical model was developed to simulate microseismicity in longwall coal mining. A 3D base case model, which represented the spatial distribution of fractures in the homogenous zone of the coal seam around the longwall panel K. $-50 / \mathrm{C}$ was constructed, calibrated and validated for modelling microseismicity for the first eight weeks of the monitoring period, before the longwall face reached the xylite-rich heterogeneous zone.

As presented in Figure 5, $b$ values and fitted mean values $\mu$ for simulated microseismicity are compared favourably with the field observations over this period. The $b$ values for recorded seismicity fall within one standard deviation of those for the modelled seismicity. This indicated that both the size scaling and average released energy of recorded microseismicity can be satisfactorily represented by the DFNbased numerical model.

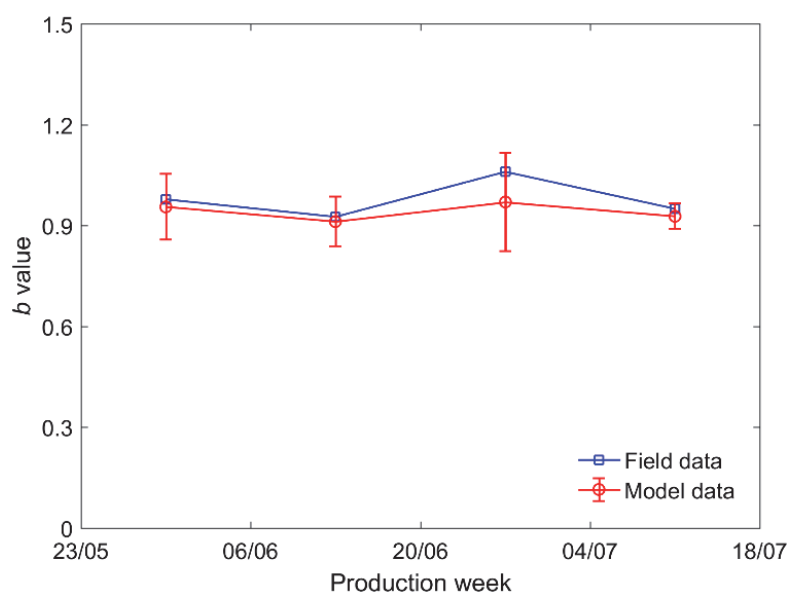

(a)

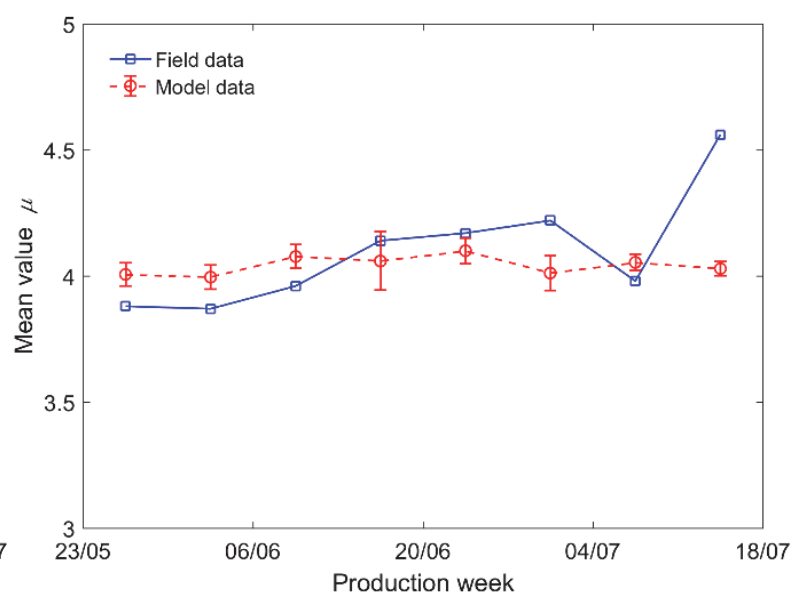

(b)

Figure 5. Validation of the numerical model for simulating microseismicity against field monitoring data during the first eight weeks of the monitoring period: (a) bi-weekly variation of $b$ values for recorded and modelled microseismic events, and (b) fitted mean value $\mu$ of weekly Gaussian parameters for recorded and modelled microseismic events (after Cao et al., 2018).

The same model, measuring $300 \mathrm{~m}$ long, $350 \mathrm{~m}$ wide and $200 \mathrm{~m}$ high, is used here to investigate the effect of lithological heterogeneity on microseismicity around the same LTCC panel. As illustrated in Figure 6a, the panel K. $-50 / \mathrm{C}$ has a thickness of $20 \mathrm{~m}$ and a width of $150 \mathrm{~m}$, including both the intake and return gateroads. The panel is underlain by $100 \mathrm{~m}$ thick floor coal, and overlain by a $20 \mathrm{~m}$ thick 
mixed roof layer. A further $50 \mathrm{~m}$ thick clay layer was on the top of the mixed layer. The geometry of the xylite-rich zone inferred from the active seismic tomography measurements was digitalised from Figure 3 and implemented into the $\mathrm{FLAC}^{3 \mathrm{D}}$ model, assuming full penetration within the coal panel. The geological structures used in the model consisted of detritic coal, clay, failed clay (for caved roof goaf) and xylitic coal (for the xylite-rich zone). Material properties of the first three structures were obtained from laboratory tests on samples from Coal Mine Velenje and are shown in Table 1. The elastic properties (bulk modulus and shear modulus) of the xylite-rich coal were set to be the same as those of detritic coal, but the strength properties (compressive and tensile strength) of xylite-rich coal were set to be one to two times those of detritic coal.

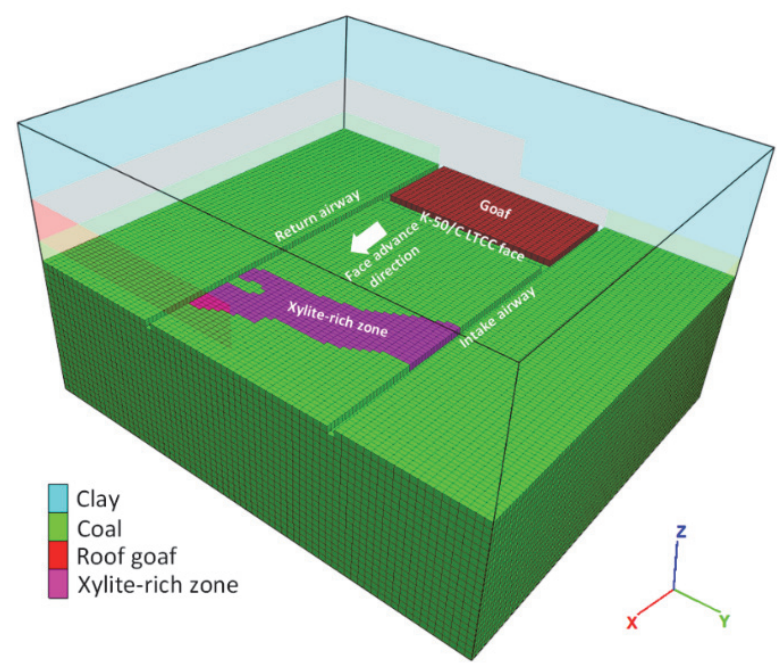

(a)

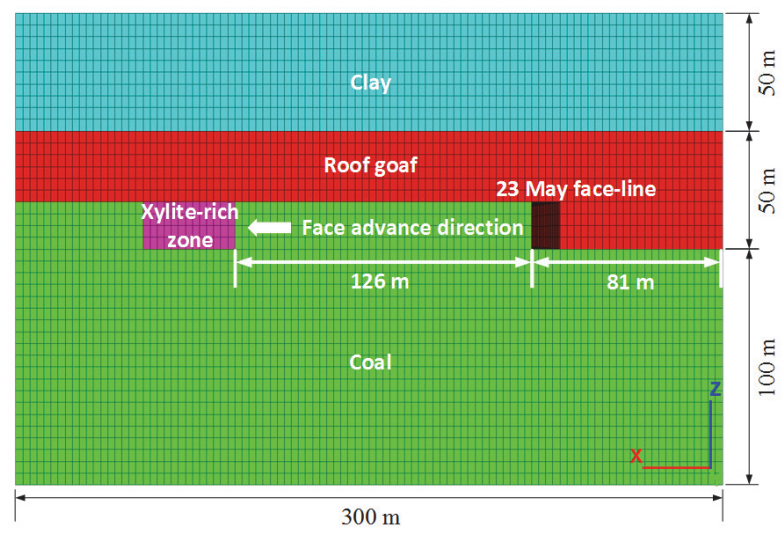

(b)

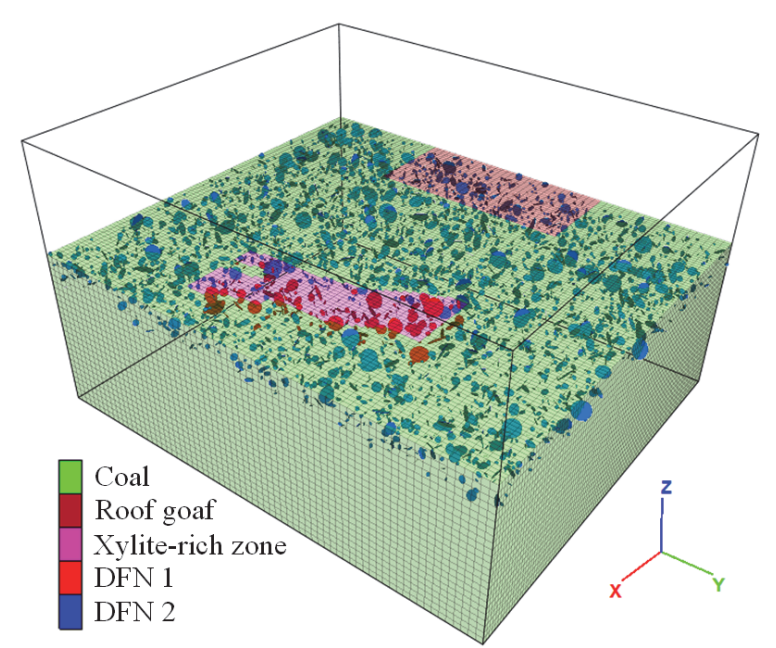

(c)

Figure 6. Mining geometry and geological implementation of the xylite-rich zone: (a) 3D model geometry, (b) the central cross-section of the model along the face advance direction, and (c) distribution of DFNs located at the panel level $[-330 \mathrm{~m},-350 \mathrm{~m}]$ following power law relationship with $a_{\mathrm{c}}=2.7, a_{\mathrm{h}}=1.8, \alpha_{\mathrm{h}}=0.7 \alpha_{\mathrm{c}}$.

The rock strata behaviour was modelled using the strain-softening constitutive model. In the post-failure stage, it was assumed that the residual cohesions of coal, clay and xylite reduce with increasing plastic strain, and that residual values of $17 \%$ of initial cohesions are achieved when the plastic strain reaches 
0.001. It was noted that roof goaf may exhibit strain hardening behaviour and affect the stress distribution along the roof goaf and stresses transferred to the abutment zone. After carrying out a sensitive study by varying hardening parameters, it was found that the strain hardening behaviour of roof goaf hardly has impacts on stress distribution ahead of the longwall face and in turn the induced microseismicity in this work.

Table 1 Rock mechanical properties used in the K.-50/C LTCC model (after Zavšek, 1993; Si et al., 2015b)

\begin{tabular}{lccccccc}
\hline Lithology & $\begin{array}{l}\text { Bulk } \\
\text { modulus } \\
(\mathrm{GPa})\end{array}$ & $\begin{array}{l}\text { Shear } \\
\text { modulus } \\
(\mathrm{GPa})\end{array}$ & $\begin{array}{l}\text { Cohesion } \\
(\mathrm{MPa})\end{array}$ & $\begin{array}{l}\text { Internal } \\
\text { friction } \\
\text { angle }\left({ }^{\circ}\right)\end{array}$ & $\begin{array}{l}\text { Tensile } \\
\text { strength } \\
(\mathrm{MPa})\end{array}$ & $\begin{array}{l}\text { Residual } \\
\text { cohesion } \\
(\mathrm{MPa})\end{array}$ & $\begin{array}{l}\text { Residual tensile } \\
\text { strength }(\mathrm{MPa})\end{array}$ \\
\hline \hline Detritic coal & 0.90 & 0.19 & 2.10 & 23 & 0.92 & 0.35 & 0.52 \\
Clay & 1.10 & 0.24 & 1.90 & 30 & 0.92 & 0.63 & 0.52 \\
Failed clay & 0.77 & 0.17 & 0.63 & 30 & 0.52 & 0.63 & 0.52 \\
\hline
\end{tabular}

The bottom of the model was fixed, and the normal stresses were applied on other boundary faces to simulate the in situ stress field. The initial vertical stress was estimated from the weight of overburden, and the initial horizontal stress was calculated based on the Poisson's effect under vertical gravity loading.

After construction of the model, two groups of fractures were embedded into the model domain: one group for the xylite-rich zone (DFN 1), and the other for the remaining zones (DFN 2). For both fracture groups, the fracture positions and orientations were set to be random, and the fracture radii ranged from $0.9 \mathrm{~m}$ to $6.5 \mathrm{~m}$. A fracture number of 44,707 and scaling exponent $a=2.7$ were applied for the DFN 2 to calibrate the synthetic microseismic intensity and size distribution to the recorded ones. The fracture number and scaling exponent for the DFN 1 were varied during modelling, and will be introduced in Section 4.2.

\subsection{Modelling scenarios}

In the current work, a total of twelve extraction steps were simulated (from right to left in Figure 6b), from 23th May to 28th August, with an interruption of a two-week holiday period starting from 18th July. To take into account the impact of previous mining activities, the intake and return gateroads and the elements representing one-week's worth of coal production (12 m long, $150 \mathrm{~m}$ wide and $20 \mathrm{~m}$ thick) behind the initial face-line were extracted. In this study, each excavation step represented coal extraction for one week. After stress equilibrium was reached at each excavation step, the stress and failure states of elements hosting fractures were checked if fracture slippage had taken place to register microseismic events, as described in Section 2.

Multiple runs were carried out with various rock strengths for the xylite-rich coal and fracture attributes within the xylite-rich zone, respectively:

(1) The geometry parameters for fractures in the heterogeneous zone remain the same as those in the detrite dominated coal seam, and four scenarios were considered by varying compressive and tensile rock strength of elements within the heterogeneous zone: (a) $\sigma_{c \mathrm{~h}}=\sigma_{c \mathrm{cc}}, \sigma_{\mathrm{th}}=\sigma_{\mathrm{tc}}$; (b) $\sigma_{c \mathrm{~h}}=$ $1.5 \sigma_{c \mathrm{c}}, \sigma_{t \mathrm{~h}}=1.5 \sigma_{t \mathrm{c}} ;$ (c) $\sigma_{\mathrm{ch}}=2 \sigma_{\mathrm{cc}}, \sigma_{t \mathrm{~h}}=2 \sigma_{\mathrm{tc}}$, and (d) $\sigma_{\mathrm{ch}}=2.5 \sigma_{c \mathrm{c}}, \sigma_{t \mathrm{~h}}=2.5 \sigma_{t \mathrm{c}}$.

where $\sigma_{c \mathrm{cc}}$ and $\sigma_{\mathrm{tc}}$ are respectively the compressive and tensile strengths of the detritic coal seam, and $\sigma_{c h}$ and $\sigma_{t h}$ are those of the heterogeneous zone.

(2) The rock strength of the heterogeneous zone remains the same as that of the detrite dominated coal seam, and four scenarios were considered by varying the fracture intensity term and size 
distribution exponent of fractures hosted by the heterogeneous zone: (a) $a_{\mathrm{h}}=2.7, \alpha_{\mathrm{h}}=\alpha_{\mathrm{c}}$; (b) $a_{\mathrm{h}}=$ 2.4, $\alpha_{\mathrm{h}}=0.9 \alpha_{\mathrm{c}} ;$ (c) $a_{\mathrm{h}}=2.1, \alpha_{\mathrm{h}}=0.8 \alpha_{\mathrm{c}}$, and (d) $a_{\mathrm{h}}=1.8, \alpha_{\mathrm{h}}=0.7 \alpha_{\mathrm{c}}$.

where $a_{\mathrm{h}}$ is the power law distribution exponent for the heterogeneous zone, and $\alpha_{\mathrm{c}}$ and $\alpha_{\mathrm{h}}$ are the fracture intensity terms for the detritic coal seam and heterogeneous zone, respectively. Since the fracture density term $\alpha$ is proportional to the fracture number in a certain volume, $\alpha_{\mathrm{h}}$ is controlled by changing the total number of fractures assigned to the heterogeneous zone. The fracture distribution for the scenario (d) is presented in Figure 6c.

In order to account for the stochastic nature of DFNs, a total of five series of DFN realisations were generated for each modelling scenario. In order to be comparable with the field monitored data available from the mine, the simulated microseismic microseismic events located in the longwall panel horizon [-330 $\mathrm{m},-350 \mathrm{~m}]$ and in the zone within $100 \mathrm{~m}$ ahead of the face-line were used for analysis. The model results and analysis in terms of frequency-magnitude distribution and logarithmic released energy are presented next.

\section{Model results}

\subsection{Influence of rock strength on seismic response}

Figure 7 presents the variation of fitted $b$ values from frequency-magnitude distribution of recorded and simulated microseismicity over the monitoring period. When the rock strength of elements within the xylite-rich zone is the same as that of detritic coal, $b$ values of microseismicity are quite consistent over the whole period. When the rock strength of elements within the xylite-rich zone is stronger than that of detritic coal matrix, there is a notable reduction in $b$ values several weeks before reaching the xyliterich zone. The reduction in $b$ values has a positive correlation with the increase in rock strength of elements within the xylite-rich zone. An average $b$ value as low as 0.67 can be fitted when approaching the xylite-rich zone for the modelling scenario $\sigma_{\mathrm{ch}}=2.5 \sigma_{\mathrm{cc}}, \sigma_{\mathrm{th}}=2.5 \sigma_{\mathrm{tc}}$.

The frequency-magnitude distribution of recorded and simulated microseismicity during 1 to 14 August 2011, when the xylite-rich zone was partly mined after a two week holiday period (no production), was also analysed. It was noted that the frequency-magnitude distribution for different modelling scenarios follows a power law relationship fairly closely, but the fitted curve becomes less steep with increasing rock strength of elements within the xylite-rich zone, i.e. the $b$ value decreases.

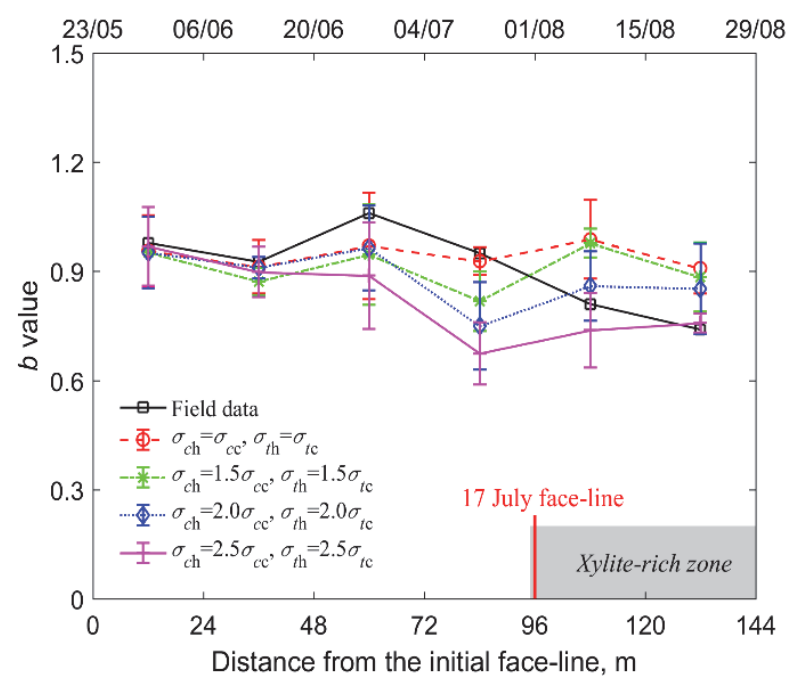


Figure 7. The bi-weekly $b$ values for frequency-magnitude distribution of the recorded and simulated microseismic events over the monitoring period.

The effect of rock strength on weekly histograms of the logarithmic event energy was analysed for the field data and modelling scenario $\sigma_{c \mathrm{c}}=2 \sigma_{c \mathrm{c}}, \sigma_{t \mathrm{~h}}=2 \sigma_{\mathrm{tc}}$ before and after reaching the xylite-rich zone, respectively. The results indicated that both the elevation in energy levels and reduction in the number of seismic events after reaching the xylite-rich zone can be modelled by increasing the rock strength of elements within the xylite-rich zone. The decrease in the number of simulated microseismic events is believed to be due to a lower chance of slippage of fractures within the stronger xylite-rich zone.

Figure 8 shows the fitted Gaussian distribution parameters to the logarithmic event energy for the recorded and simulated seismicity over the monitoring period. With the same rock strength for detritic coal and xylite-rich coal, both $\mu$ and $\sigma$ of the logarithmic energy are fairly consistent during the twelveweek modelling period, fluctuating around 4.0 and 0.65 , respectively. In contrast, strong rock strength for xylite-rich coal leads to a marked increase in both $\mu$ and $\sigma$ when the xylite-rich zone is approached. $\mu$ and $\sigma$ peak within one week before or after reaching the xylite-rich zone, and gradually decline until the end of the monitoring period. This is justified by the fact that more microseismic events releasing relatively large energy happen in the xylite-rich zone, shifting the domain of distribution to the right as well as stretching this domain.

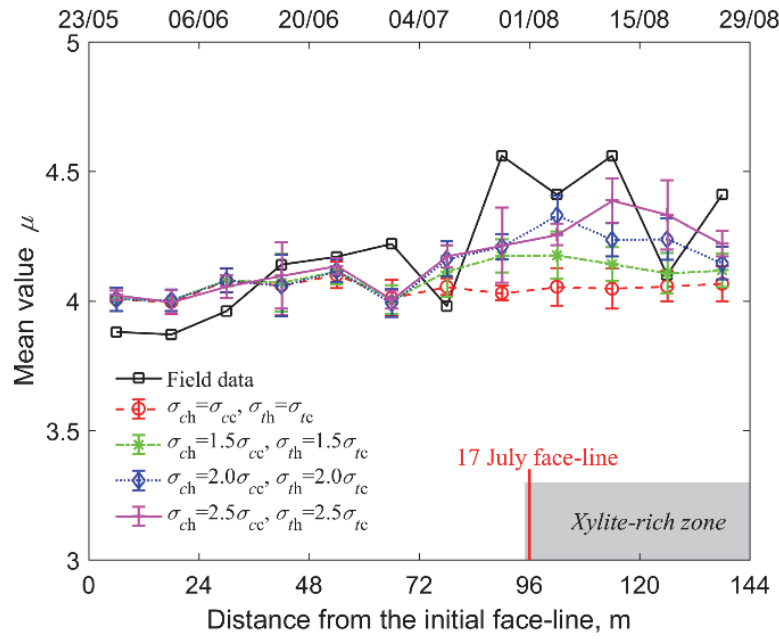

(a)

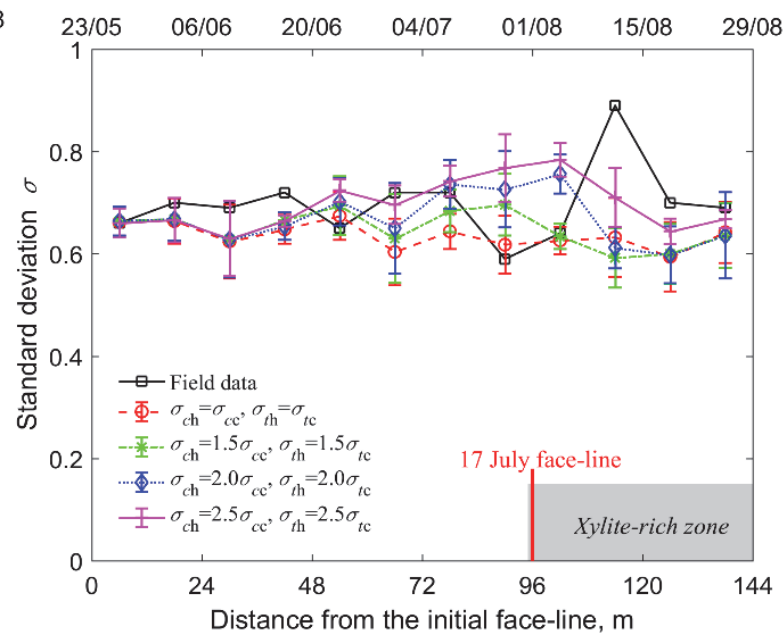

(b)

Figure 8. The fitted Gaussian distribution parameters to the logarithmic event energy for the recorded and simulated seismicity over the monitoring period: (a) mean value $\mu$, and (b) standard deviation $\sigma$.

Figure 9a presents the variation of the simulated average resultant stress drop in each week during face advance towards the xylite-rich zone. It can be seen that for the scenario with strong xylite-rich coal, the resultant average stress drop remains quite consistent during the first few production weeks, increases up to three weeks before the xylite-rich zone is encountered and fluctuates until the end of the monitoring period.

In order to analyse the magnitude distribution of stress drops during coal extraction, the histograms of stress drops during two typical production weeks for the scenario $\sigma_{c \mathrm{~h}}=2 \sigma_{c \mathrm{c}}, \sigma_{\mathrm{th}}=2 \sigma_{\mathrm{tc}}$ are plotted in 
Figure 9b. It can be seen that stress drops form two clusters for the week 30 May to 5 June. Considering various rock strength properties for different geological structures, it is deduced that stress drops from events occurring in coal and clay range from 0.84 to $1.08 \mathrm{MPa}$, and that those from events taking place in roof goaf are between 0.25 and $0.42 \mathrm{MPa}$. In contrast, one more cluster ranging from 2.17 to 2.33 $\mathrm{MPa}$, corresponding to microseismic events occurring in the xylite-rich zone, is observed during the week 1 to 7 August. The average stress drop in this cluster is more than twice that of the events happening in detritic coal and clay. In addition, the number of events that occur in detritic coal and clay decreases remarkably. Therefore, the energy released from microseismic events is enhanced when the xylite-rich zone is reached.

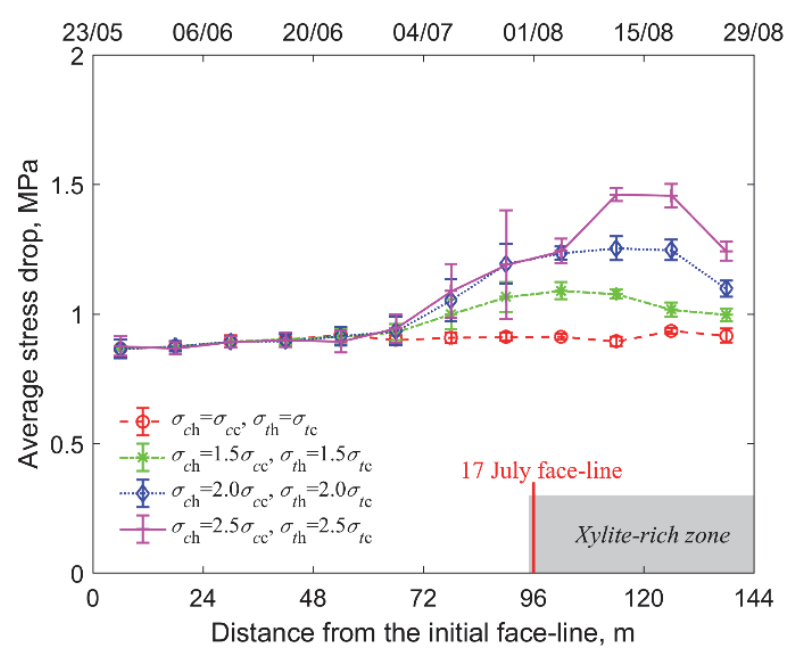

(a)

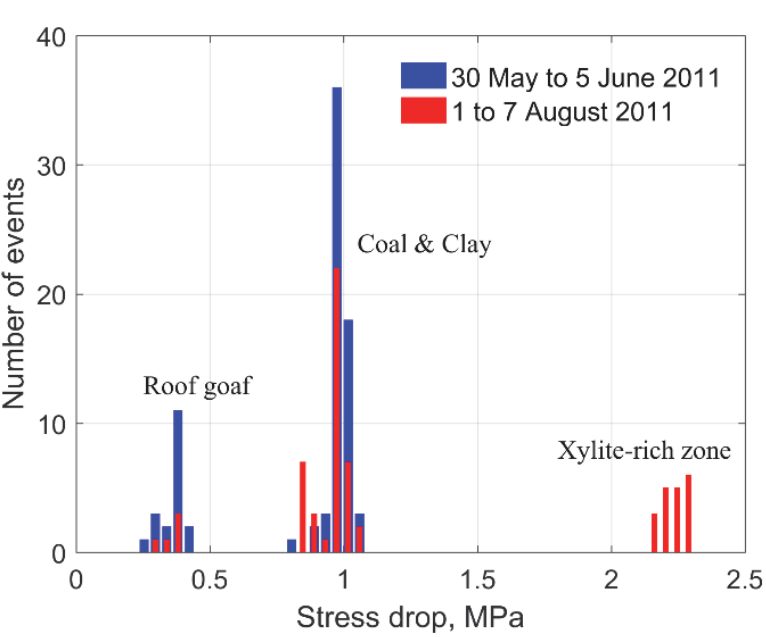

(b)

Figure 9. (a) Simulated average stress drops over the twelve-week monitoring period, and (b) examples of histograms of stress drops for the scenario $\sigma_{c \mathrm{~h}}=2 \sigma_{c \mathrm{c}}, \sigma_{t \mathrm{~h}}=2 \sigma_{t c}$.

\subsection{Influence of fracture attributes on seismic response}

Figure 10a presents the variation of fitted $b$ values from frequency-magnitude distribution of recorded and simulated microseismicity over the monitoring period. For modelling scenarios with lower power law length exponent $a$ of embedded fractures within the xylite-rich zone, $b$ values of mining-induced microseismicity begin to decrease during 20 June to 3 July and reach the bottom just before encountering the xylite-rich zone. The lower the length exponent $a_{\mathrm{h}}$ of embedded fractures within the xylite-rich zone, the larger the reduction in fitted $b$ values of simulated microseismicity. An average $b$ value as low as 0.72 can be fitted when approaching the xylite-rich zone for the modelling scenario $a_{\mathrm{h}}$ $=1.8, \alpha_{\mathrm{h}}=0.7 \alpha_{\mathrm{c}}$.

Figure 10b shows an example of the frequency-magnitude distribution of recorded and simulated microseismicity during a two-week period after reaching the xylite-rich zone. The frequency-magnitude distribution for different modelling scenarios remains a power law relationship, with the slope ( $b$ value) positively correlated with the length exponent $a_{\mathrm{h}}$ of embedded fractures within the xylite-rich zone. When $a_{\mathrm{h}}=1.8, \alpha_{\mathrm{h}}=0.7 \alpha_{\mathrm{c}}$, the fitted $b$ value is in good agreement with that of recorded microseismicity. 


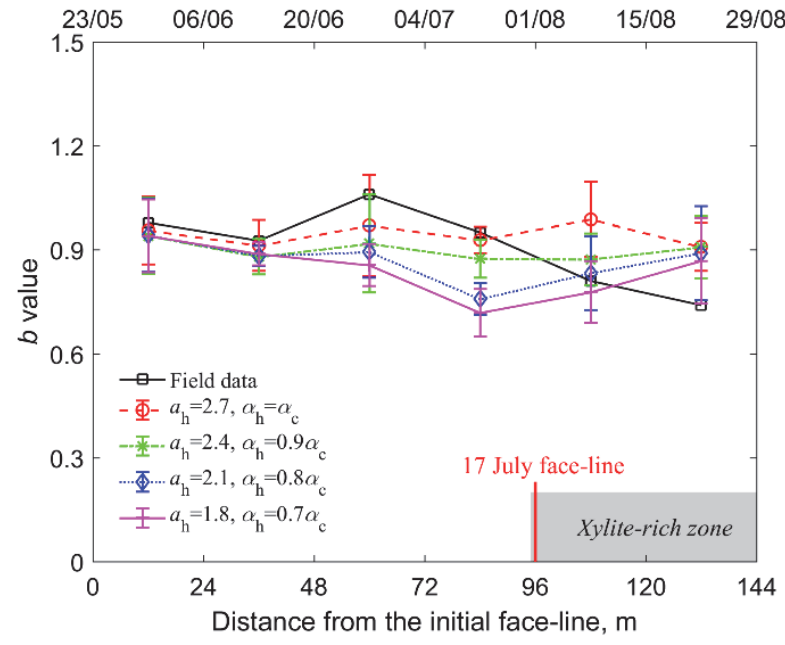

(a)

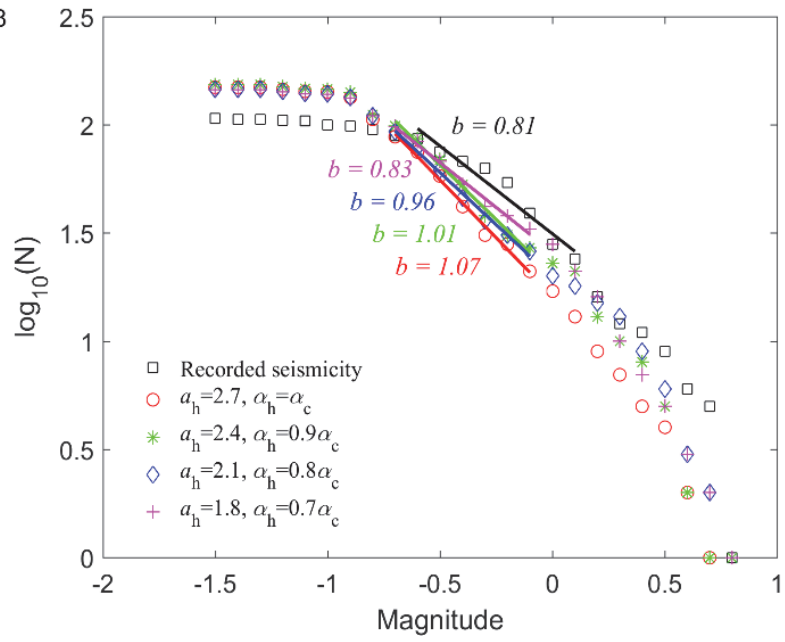

(b)

Figure 10. (a) The bi-weekly $b$ values for frequency-magnitude distribution of the recorded and simulated microseismic events over the monitoring period, and (b) examples of $b$ values obtained through regression fitting for the recorded and simulated microseismic events during 1 to 14 August 2011, when the xylite-rich zone was partly mined after a two week no production holiday period.

Figure 11 presents examples of weekly histograms of the logarithmic event energy for the field data and modelling scenario $a_{\mathrm{h}}=1.8, \alpha_{\mathrm{h}}=0.7 \alpha_{\mathrm{c}}$ before and after reaching the xylite-rich zone, respectively. It can be observed that the rightward shift of bins to higher energy levels after encountering the xyliterich zone can be simulated with lower $a_{\mathrm{h}}$ values. In addition, the number of simulated microseismic events decreases after reaching the xylite-rich zone, as observed in the recorded microseismicity.

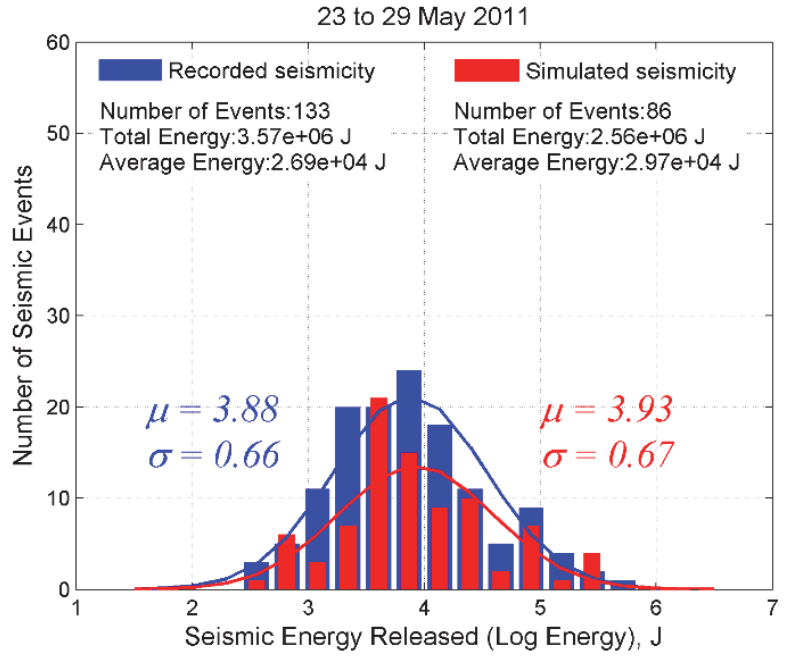

(a)

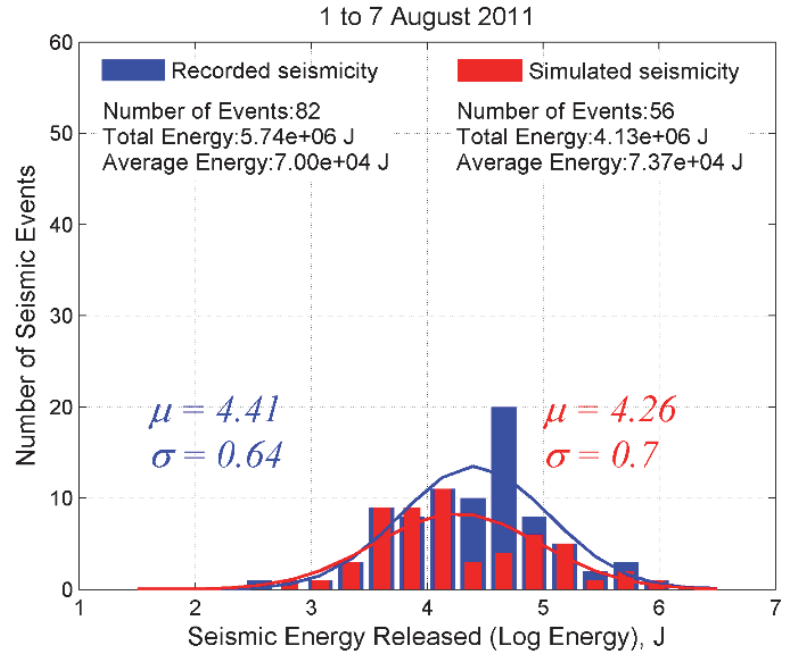

(b)

Figure 11. Examples of weekly histograms of the logarithmic event energy for the recorded seismicity and simulated seismicity for the scenario $a_{\mathrm{h}}=1.8, \alpha_{\mathrm{h}}=0.7 \alpha_{\mathrm{c}}$ : (a) during Week 23 to 29 May 2011, and (b) during Week 1 to 7 August 2011. 
The effect of fracture attributes on fitted Gaussian distribution parameters to the logarithmic event energy was also analysed for the recorded and simulated seismicity over the monitoring period. The results have indicated that low length exponents $a_{\mathrm{h}}$ of embedded fractures within the xylite-rich zone lead to a slight increase in $\mu$ and a noticeable increase in $\sigma$ when the xylite-rich zone is reached. This is the result of increased slippage chance of relatively large fractures within the xylite-rich zone given a lower $a_{\mathrm{h}}$ value. However, low $a_{\mathrm{h}}$ values alone, even as low as 1.8 , cannot completely account for the remarkable increases in both $\mu$ and $\sigma$ of the logarithmic energy of the recorded microseismicity.

The slipped fracture size is closely associated with the seismic energy release. It can be observed from Figure 12a that the weekly average slipped fracture size is fairly steady over the monitoring period for the scenario $a_{\mathrm{h}}=2.7, \alpha_{\mathrm{h}}=\alpha_{\mathrm{c}}$, but experiences an increase when approaching the xylite-rich zone for modelling scenarios with lower $a_{\mathrm{h}}$ values. This is consistent with the variation trend of weekly fitted average value $\mu$ of the logarithmic energy. It is noted that, even for the same modelling scenario, there is a noticeable difference between the average slipped fracture sizes obtained from different DFN realisations. This discrepancy can be attributed to the intrinsic stochastic nature in size distribution and spatial distribution of embedded fractures.

In order to analyse the distribution and variation of slipped fracture sizes, the weekly histograms for two production weeks for the scenario $a_{\mathrm{h}}=1.8, \alpha_{\mathrm{h}}=0.7 \alpha_{\mathrm{c}}$ are plotted in Figure 12b. For both coal production weeks, the larger the slipped fracture sizes, the lesser the number of slipped fractures. During the week 1 to 7 August, however, there is a much smaller number of small slipped fracture sizes on the left of the histogram, followed by a longer tail comprising of relatively large slipped fracture sizes. The maximum slipped fracture size also increases from less than $5.5 \mathrm{~m}$ during the week 30 May to 5 June to over $6.0 \mathrm{~m}$ during 1 to 7 August. Therefore, the less dominance of small slipped fractures within the xylite-rich zone (lower $a_{\mathrm{h}}$ values) contributes to the increase in the average slipped fracture size when reaching the xylite-rich zone.

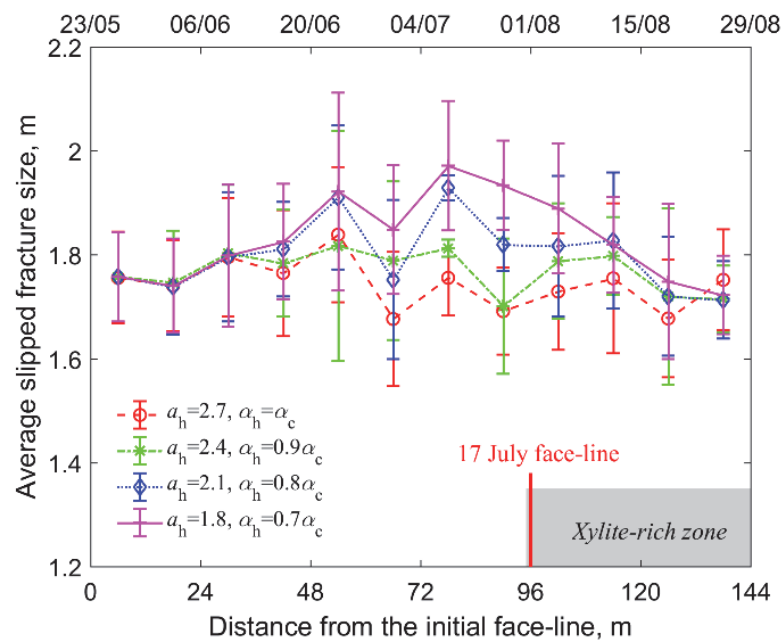

(a)

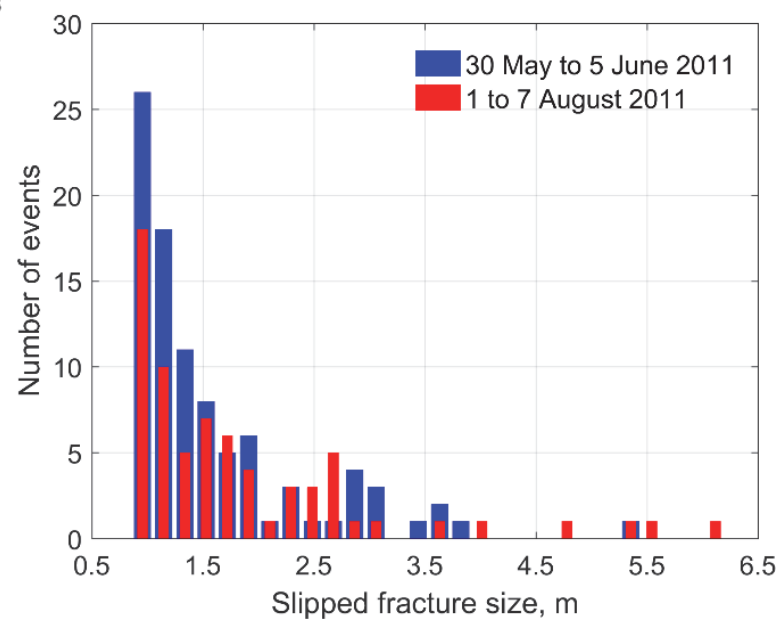

(b)

Figure 12. (a) Simulated average slipped fracture sizes over the twelve-week monitoring period, and (b) examples of histograms of average slipped fracture sizes for the scenario $a_{\mathrm{h}}=1.8, \alpha_{\mathrm{h}}=$ $0.7 \alpha_{\mathrm{c}}$. 


\section{Discussion}

Material heterogeneity and geological discontinuities can contribute to rock failure and even increased hazard potential. However, there have been no systematic investigations regarding the influence of material heterogeneity or geological discontinuities on microseismic occurrences and evolution, as most current numerical modelling research are based on continuum mechanics which is limited to deterministic stress and fracture analyses. To address this problem, research presented in this paper modelled microseismic occurrences by taking the stochastic nature of microseismicity into account.

A higher strength xylite-rich coal zone was detected in the K. -50/C LTCC panel at Coal Mine Velenje during active seismic tomography research. It has been observed that, during the week 11 to 17 July 2011 , the largest microseismic events were recorded in a region 40 to $\sim 60 \mathrm{~m}$ ahead of the advancing face, overlapping with the xylite-rich zone. It has also been noted that the microseismicity underwent a reduction in fitted $b$ values from frequency-magnitude distribution and an increase in fitted Gaussian distribution parameters during this period.

As shown in Equation (4), the seismic energy released is proportional to the square of stress drop. Given that the strength of xylite-rich coal is higher than that of detritic coal, less fracturing would be expected to take place in xylite-rich coal, and thus less intensity in microseismicity, than in detritic coal under the same stress conditions. However, once failure has occurred in the xylite-rich zone, the associated stress drop, and thus seismic energy released, would be much larger than those in the surrounding detritic coal matrix.

Similarly, the seismic energy released is proportional to the cube of fracture size (Equation (4)). Given that less fractures are embedded within the xylite-rich zone, less microseismic events would occur in xylite-rich coal under the same stress conditions. In addition, a larger proportion of large fractures within the xylite-rich zone would lead to a larger chance of slippage for large fractures, and thus increased seismic energy release under the same stress conditions.

It is noticed that the decrease in fitted $b$ values from frequency-magnitude distribution (Figure 7 and Figure 10) and the increase in fitted Gaussian distribution parameters (Figure 8) begin several weeks before reaching the xylite-rich zone in the models. Considering that mining-induced microseismic events can take place up to 80-100 m ahead of a longwall face-line, seismic characteristics of events from a heterogeneous zone can be detected before the zone is reached. In this respect, seismic anomaly may be utilised as a precursory indicator for abnormal geological stratum or fracture attributes.

\section{Conclusions}

In the present study, the progressive advance of a longwall face towards a xylite-rich coal zone during a twelve-week period at Coal Mine Velenje was simulated in FLAC ${ }^{3 \mathrm{D}}$. A newly developed DFN-based numerical approach combining stress analysis and fracture evaluation was utilised to simulate the induced microseismic occurrences and associated energy release. The heterogeneity of the xylite-rich zone was taken into account by varying rock strength of the xylite-rich coal and fracture attributes within the xylite-rich zone, respectively.

When the longwall face-line is far from the xylite-rich zone, the fitted $b$ values from frequencymagnitude distribution and fitted Gaussian distribution parameters of microseismicity are fairly consistent during the coal extraction period, which is in agreement with the field observations. Once higher strength properties were assigned to the xylite-rich coal elements or fractures with lower fracture intensity and scaling exponent were embedded within the xylite-rich zone, a reduction in fitted $b$ values and an increase in fitted Gaussian distribution parameters were observed as the longwall face approached the heterogeneous zone. Therefore, both the high rock strength of xylite-rich coal and low scaling exponent of fractures within the xylite-rich zone contribute to these deviations. These deviations 
are believed to result from the combined effects of increased stress drops and slipped fracture sizes when the xylite-rich zone is approached. The results of this study can provide implications for a precursory detection of abnormal geological strata and fracture attributes.

\section{Acknowledgements}

This research is carried out as part of the project "Monitoring, Assessment, Prevention and Mitigation of Rock Burst and Gas Outburst Hazards in Coal Mines-MapROC" funded by the European Commission Research Fund for Coal and Steel (RFCS), Grant No: RFCR-CT-2015-00005. The authors would like to express their gratitude to the European Commission for funding this research. The first author also acknowledges the Engineering and Physical Sciences Research Council (EPSRC) scholarship awarded by the Department of Earth Science and Engineering, Imperial College London. The authors would also like to thank colleagues at K-UTEC AG Salt Technologies of Germany, who has implemented the time-lapse seismic tomography underground, and colleagues from the Central Mining Institute (GIG) of Poland who carried out the passive microseismic monitoring at the mine.

\section{References}

Abolfazlzadeh, Y., \& Hudyma, M (2016). Identifying and Describing a Seismogenic Zone in a Sublevel Caving Mine. Rock Mechanics and Rock Engineering, DOI: 10.1007/s00603-016-1017-x, 1-17.

An, F. H., \& Cheng, Y. P. (2013). An explanation of large-scale coal and gas outbursts in underground coal mines: the effect of low-permeability zones on abnormally abundant gas. Natural Hazards and Earth System Sciences Discussions, 1, 4751-4775.

Board, M. (1994). Numerical examination of mining-induced seismicity (Doctoral dissertation, University of Minnesota).

Bonnet, E., Bour, O., Odling, N. E., Davy, P., Main, I., Cowie, P., Berkowitz, B. (2001). Scaling of fracture systems in geological media. Reviews of geophysics, 39(3), 347-383.

Cao, W., Shi, J. Q., Si, G., Durucan, S., \& Korre, A. (2018). Numerical modelling of microseismicity associated with longwall coal mining. International Journal of Coal Geology, 193, 30-45.

Harthong, B, Scholtès L, Donzé FV. Strength characterization of rock masses, using a coupled DEM-DFN model. Geophysical Journal International. 2012 Nov 1;191(2):467-80.

Jeromel, G., Medved, M., Likar, J. (2010). An analysis of the geomechanical processes in coal mining using the Velenje mining method, Acta Geotechnica Slovenica, vol. 7, no. 1, pp.31-45.

Lei, X., Masuda, K., Nishizawa, O., Jouniaux, L., Liu, L., Ma, W., ... \& Kusunose, K. (2004). Detailed analysis of acoustic emission activity during catastrophic fracture of faults in rock. Journal of Structural Geology, 26(2), 247-258.

Sainoki, A., \& Mitri, H. S. (2014). Methodology for the interpretation of fault-slip seismicity in a weak shear zone. Journal of Applied Geophysics, 110, 126-134.

Salamon, M. D. G. (1993). Keynote address: Some applications of geomechanical modelling in rockburst and related research. In Proceedings of the 3rd International Symposium on Rockbursts and Seismicity in Mines, 297-309. Rotterdam: AA Balkema.

Sato, K., \& Fujii, Y. (1988). Induced seismicity associated with longwall coal mining. International Journal of Rock Mechanics and Mining Sciences \& Geomechanics Abstracts, 25(5), 253-262.

Si, G., Durucan, S., Jamnikar, S., Lazar, J., Abraham, K., Korre, A., ... \& Lurka, A. (2015a). Seismic monitoring and analysis of excessive gas emissions in heterogeneous coal seams. International Journal of Coal Geology, 149, 41-54. 
Si, G., Shi, J. Q., Durucan, S., Korre, A., Lazar, J., Jamnikar, S., \& Zavšek, S. (2015b). Monitoring and modelling of gas dynamics in multi-level longwall top coal caving of ultra-thick coal seams, Part II: Numerical modelling. International Journal of Coal Geology, 144, 58-70.

Spottiswoode, S. M. (1984). Source mechanisms of mine tremors at Blyvooruitzicht gold mine. Rockbursts and Seismicity in Mines, (6), 29-37.

Stiller, H., Hustig, E., Grosser, H. \& Knoll, P. (1983). On the nature of mining tremors. Journal of Earthquake Prediction Research, 2: 61.

Swanson, P. L. (1992). Mining-induced seismicity in faulted geologic structures: An analysis of seismicityinduced slip potential. Pure and applied geophysics, 139(3-4), 657-676.

Xu, D. P., Feng, X. T., Cui, Y. J., \& Jiang, Q. (2015). Use of the equivalent continuum approach to model the behavior of a rock mass containing an interlayer shear weakness zone in an underground cavern excavation.Tunnelling and Underground Space Technology, 47, 35-51.

Zavšek, S., 1993.Stabilnost jamskih progc: Stability of mine roadways. MSc thesis (in Slovene), Ljubljana, 84.

Zhao, K., Janutolo, M., Barla, G., \& Chen, G. (2014). 3D simulation of TBM excavation in brittle rock associated with fault zones: The Brenner Exploratory Tunnel case. Engineering Geology, 181, 93-111. 